\title{
O letramento literário no Ensino Médio sob a perspectiva dos multiletramentos
}

\section{The literary literary in Middle School under the perspective of multiletraments}

\author{
Sandra Noeli Rezende de Oliveira Barboza* \\ Universidade Estadual de Mato Grosso do Sul \\ Campo Grande, Mato Grosso do Sul, Brasil \\ Neide Araujo Castilho Teno* \\ Universidade Estadual de Mato Grosso do Sul \\ Campo Grande, Mato Grosso do Sul, Brasil \\ Emilio Davi Sampaio*** \\ Universidade Estadual de Mato Grosso do Sul, \\ Campo Grande, Mato Grosso do Sul, Brasil
}

\begin{abstract}
Resumo: O presente artigo tem a finalidade de realizar um estudo teórico da concepção de Letramento Literário, na perspectiva da pedagogia dos Multiletramentos. Os avanços tecnológicos e a grande influência das novas tecnologias da informação e da comunicação e as questões multiculturais, têm exigido do ensino da linguagem e da literatura, enfoques de leitura que considerem os aspectos polifônicos, colaborativos, híbridos, mestiços, onipresentes e polissêmicos dos textos literários. Como metodologia de pesquisa, recorremos à pesquisa explanatória de cunho bibliográfico, com teóricos como Cosson (2014a, 2014b), Candido (2000), Rezende (2013), Bakhtin (2003), Chartier (1999), Rojo (2012) e Canclini (2008). O estudo discute o lugar e a importância da literatura para a formação intelectual, linguística, cultural e humana dos sujeitos, e a possibilidade da realização de práticas de multiletramentos, buscando destacar as questões éticas e estéticas subjacentes às atuais práticas multiletradas e às concepções literárias no bojo do referencial teórico disponível.
\end{abstract}

Palavras-chave: Letramento literário. Multiletramentos. Ensino de literatura.

\begin{abstract}
The presente article has the finality of a theoretical study of Literary Literacy conception, from the perspective of the pedagogy of Multiletramentos. Technological advances and the great influence of the new information and communication technologies and the multicultural, have required the teaching of language and literature, reading approaches that consider the polyphonic, collaborative, hybrid, mestizo, omnipresent and polysemic aspects of texts Literary works. As a research methodology, We resorted to the explanatory research of bibliographic, With theorists such as Consson (2014a, 2014b), Candido (2000), Rezende (2013), Bakhtin (1992), Chartier (1999), Rojo (2012) and Canclini. The study discusses the place and importance of literature for the intellectual, linguistic, cultural and human formation of subjects, and the possibility of performing multilearning practices, seeking to highlight the ethical and aesthetic issues underlying current multiletracies practices and literary conceptions in Theoretical reference available.
\end{abstract}

Keywords: Literary literacy. Multiletramentos. Literature teaching.

\footnotetext{
* Aluna do Mestrado em Letras da Universidade Estadual de Mato Grosso do Sul. Linha de pesquisa: Ensino de Linguagens. Membro do grupo de Estudo e Pesquisa em Narrativas Formativas (GEPENAF). E-mail noelifer70@yahoo.com.br.

** Professora Doutora da Universidade Estadual de Mato Grosso do Sul, UEMS, Curso de Letras. Professora da Pós Graduação Mestrados em Letras Profissional e Profletras da UEMS, Linhas de pesquisa: Linguagem e Ensino e Texto e Formação Docente . Vice-líder Grupo de Estudo e Pesquisa em Narrativas Formativas (GEPENAF). E-mail cteno@uol.com.br.

*** Professor Doutor da Universidade Estadual de Mato Grosso do Sul, UEMS. Professor dos Cursos Graduação, Pós Graduação Lato Sensu e Mestrado profissional - Profletras da UEMS. Professor formador da Olimpíada da Língua Portuguesa no Estado de Mato Grosso do Sul. E-mail: emilio@uems.br.
} 


\section{INTRODUÇÃO}

Propor um estudo que versa sobre o Letramento Literário no Ensino Médio à luz dos multiletramentos é um desafio muito grande, pois pressupõe uma reflexão sobre o ensino da literatura em épocas de globalização, avanços tecnológicos e sobre o leitor literário, uma vez que os leitores são outros, as necessidades estéticas e éticas pressupõem novos padrões de comportamento diante da leitura e da obra literária. A literatura tem se constituído numa área de conhecimento valiosa para a formação de leitores, e tem se modificado ao longo dos tempos, entre as diferentes culturas, e na contemporaneidade ela tem sido apreciada em todas as sociedades letradas. As obras que a constitui são importantes e perpassam o tempo, deixando um legado valioso que requer leitores vários, que possam se relacionar em todos os espaços e tempos, como nos mostra Candido (2000):

[...] quando nos colocamos ante uma obra, ou uma sucessão de obras, temos vários níveis possíveis de compreensão, segundo o ângulo em que nos situamos. Em primeiro lugar, os fatores externos, que a vinculam ao tempo e se podem resumir na designação de sociais; em segundo lugar o fator individual, isto é, o autor, o homem que a intentou, e realizou, e está presente no resultado; finalmente, este trabalho, o texto, contendo, os elementos anteriores e outros, específicos, que os transcendem e não se deixam reduzir a eles" (CANDIDO, 2000, p.33).

Nesse sentido, quando a literatura aponta os fatores externos vinculados ao tempo, ela costura idas e vindas declarando impressões, paixões acontecimentos que no dizer de Cândido (2000, p.33) trata de "uma realidade autônoma, cujo valor está na fórmula que obteve para plasmar elementos não-literários, impressões, paixões, ideias, fatos, conhecimentos, que são a matéria-prima do ato criador”. Um fator importante que está ligado não só à expressão de aspectos da realidade social e/ou individual, mas pela forma porque se faz, porque que se cria, enfim, pelo enorme e imponente ato criador. Nesse sentido, para adentrar ao mundo de uma obra literária, compreendê-la e apreciá-la faz-se necessário, entender que a autonomia de quem produz, é a eficácia das palavras, os elementos expressivos, o jogo das imagens, cujo resultado está ligado à obra como um todo.

O letramento literário no Ensino Médio possibilita, aos alunos, vivências e práticas de relação e interação, com o domínio da leitura, e proporciona-lhes um desenvolvimento crítico. Os avanços tecnológicos e a grande influência das novas tecnologias da informação e da comunicação, bem como as questões multiculturais, têm exigido do ensino da linguagem e da literatura, enfoques de leitura que considerem os aspectos polifônicos, colaborativos, híbridos, mestiços, onipresentes e polissêmicos dos textos literários.

A relação da literatura com o letramento encontra-se fundamentada enquanto "um conjunto de práticas sociais que usam a escrita, enquanto sistema simbólico e enquanto tecnologia, em contextos específicos, para objetivos específicos" (KLEIMAN, 2004, p.19), um conceito bastante pertinente para o viés dos estudos literários. Assim, este artigo 
tem a finalidade de realizar um estudo teórico acerca da concepção de Letramento Literário, na perspectiva da pedagogia dos Multiletramentos. O recorte que realizamos para este estudo aborda as questões do letramento literário sob a égide do multiletramento, e se insere em uma pesquisa maior em andamento intitulada "Multiletramento no ensino médio: a prática do professor e a avaliação da aprendizagem", vinculada ao Programa de Mestrado em Letras, Universidade Estadual de Mato Grosso do Sul (UEMS) e aos grupos de Pesquisa Linguagem e Ensino cadastrado no CNPq e Estudo e Pesquisa em Narrativas Formativas (GEPENAF).

Nesse sentido, esse recorte de estudo, justifica-se, não só pela relevância da temática para o desenvolvimento social do sujeito, como para compreender que as práticas leitoras no Ensino Médio podem ocorrer em diferentes gêneros textuais, conforme aponta Bakhtin (2003), inclusive nos literários. A literatura sendo entendida como um bem cultural, ela tanto permite o acesso às competências leitoras do sujeito letrado ou não, como proporciona a sensibilidade e conhecimento dos aspectos cognitivos e linguísticos, à medida que o professor considere todas as formas de escrita e de leitura, e, em particular a escrita e a leitura literária.

\section{A LITERATURA NO ENSINO MÉDIO E A ESCOLA}

Por que falar da literatura no Ensino Médio? Um recorte proposital dado à frequência de equívocos que tem ocorrido, de que ensinar literatura no ensino médio restringe-se premente pela proximidade do vestibular. Apreciando ou não as narrativas literárias, o aluno nessa etapa da sua formação já deveria apresentar-se como um leitor literário e crítico. Porém, o que se observa, é que, mesmo sendo a escola o espaço ideal para a leitura de obras literárias, evidencia-se, nos alunos desta etapa de ensino, uma grande dificuldade de leitura e de compreensão, e que estes, muitas vezes, não são capazes de ler uma obra inteira, relacioná-las com as questões sociais, fazendo com que a literatura passe a ser constituída, apenas, como um componente curricular, ensinado e apreendido em sua periodização de datas, locais, fases, listas de obras e autores, pouco contribuindo para a compreensão da literatura enquanto um bem cultural ou social.

Esse descuido da leitura dos textos literários de forma fragmentada, e não da obra toda, priorizando os aspectos estruturais das obras literárias, explica Cosson (2014a), que, no ensino médio, o ensino da literatura, na maioria das vezes se resume no livro didático e o conteúdo ensinado restringe-se sobre as caraterísticas do autor, das escolas literárias, "raras são as oportunidades de leitura de um texto integral, e, quando isso acontece, seguese o roteiro do ensino fundamental com preferência para o resumo e os debates" (COSSON, 2014a, p. 23). Percebe-se que o ensino da literatura encontra-se em crise, sem que haja um objeto real de estudo, um conhecimento teórico adequado, e que propicie ao aluno, prazer, reflexão, liberdade de escolhas, compromisso com o conhecimento, como proposto por Cosson (2014a),

[...] Estamos diante da falência do ensino da literatura. Seja em nome da ordem, da liberdade ou do prazer, o certo é que a literatura não está sendo ensinada para garantir a função essencial de construir e reconstruir a palavra que nos humaniza. Em primeiro lugar porque 
falta um objeto próprio de ensino. Os que se prendem aos programas curriculares escritos a partir da história da literatura precisam vencer uma noção conteudística do ensino para compreender que, mais que um conhecimento literário, o que se pode trazer ao aluno é uma experiência de leitura a ser compartilhada. (COSSON, 2014, p. 23).

Este estudioso posiciona-se a favor da descaraterização da literatura escolarizada que preocupa-se tão somente com resolução de exercícios para compreensão do período da escola literária. Aposta numa aprendizagem que envolve os conhecimentos múltiplos, como por exemplo: a geografia, a história, a teoria e a crítica. Um ensino desta natureza certamente evoca saberes e habilidades que a prática da literatura proporciona aos seus leitores. (COSSON, 2014a, p. 47). Nessa mesma linha de raciocínio, posiciona-se Cosson (2014) acerca de três perspectivas metodológicas: a técnica da oficina, a técnica do andaime e a do portifólio, que considera ideal para a sistematização do ensino de literatura. A finalidade do estudioso é mostrar aos professores as estratégias para o ensino da literatura de forma que contemple as práticas leitoras em diferentes gêneros. Assim explica tais perspectivas:

\footnotetext{
A1 ${ }^{a}$ dessas perspectivas é a técnica bem conhecida da oficina. Sob máxima de aprender a fazer fazendo, ela consiste em levar o aluno a construir pela prática seu conhecimento.

A $2^{\mathrm{a}}$ perspectiva é a técnica do andaime. Trata-se de dividir com o aluno, e em alguns casos, transferir para ele a edificação do conhecimento. Ao professor cabe atuar como um andaime, sustentando as atividades a serem desenvolvidas de maneira autônoma pelos alunos.

A $3^{a}$ perspectiva é a do portfólio. Tomando de empréstimo das áreas de publicidade e finanças, passando pelas artes visuais, o uso do portfólio oferece ao aluno e ao professor a possibilidade de registrar as diversas atividades realizadas. (COSSON, 2014a, p. 48).
}

Essas três perspectivas metodológicas apontadas pelo pesquisador, de certa forma são construídas considerando o tempo de eficácia dos estudos literários. A primeira concentra-se na prática de ministrar oficinas em busca de conhecimento. São atividades práticas, realizadas no interior das escolas que o aluno compõe, cria sua literatura. A técnica do andaime trabalha com partilhamento de responsabilidades, o professor partilha as ações com os alunos ou transfere o aperfeiçoamento do conhecimento. A atuação de quem ensina é que torna um andaime, aquele que sustenta para chegar à autonomia humana. Os estudos que ora desenvolvemos busca um professor andaime em sala de aula, à medida que, este propõe atividades de reconstrução do saber literário, por meio de pesquisa e execução de projetos. A do portifólio funciona como uma interdisciplinaridade, porque recorre às demais áreas do conhecimento, envolvendo as artes visuais, a pintura, a publicidade, o jogo de imagem, como meio de registrar as diversas atividades realizadas em um curso e com isso avaliá-las.

Outra estratégia para a formação do leitor literário recai sobre o planejamento do professor. É ele que seleciona, escolhe quais textos, e de que suportes pode utilizar para o ensino da literatura. Estudiosos como Rouxel (2013) e Rojo (2012) fazem propostas similares de complementaridade para os estudos literários. Enquanto a primeira considera os gêneros tradicionais a porta de entrada para o ensino, e, a partir de então apresenta os novos gêneros com diversidade histórica (obras canônicas, clássicas), "indo desde a literatura nacional à estrangeira incluindo as traduzidas, do passado e do presente que se 
abrem para outras culturas e constituem lugares de compartilhamento simbólico na era da globalização" (ROUXEL, 2013, p. 24). A segunda destaca a leitura como um ato discursivo, considerando as relações entre os textos, a contextualização da produção do texto e buscando realizar nas relações intertextuais e interdiscursivas apreciações de ordem política, estética e afetiva. Entre os estudiosos verifica-se uma complementação e não um distanciamento nas estratégias para a formação do leitor literário.

Diante das argumentações postas, e frente aos problemas enfrentados em relação ao ensino da literatura no ensino médio, a questão da leitura, e como esta se apresenta nas escolas é um fator bastante relevante e que merece reflexão. Assim, entendendo a leitura, na concepção de Chartier (1999, p.77) para quem "a leitura é sempre apropriação, invenção, produção de significados" a leitura depreende-se os significados, e esses significados são diálogos firmados entre o autor, a obra e o leitor, assim o ensino precisa necessariamente, voltar-se para essas características, caso o professor deseja despertar o interesse dos alunos e formar leitores. Ainda, de acordo com Chartier,

[...] todo leitor diante de uma obra a recebe em um momento, uma circunstância, uma forma específica e, mesmo quando não tem consciência disso, o investimento afetivo e intelectual que ele nela deposita está ligado a este objeto e a esta circunstância. Vemos, portanto que, de um lado, há um processo de desmaterialização que cria uma categoria abstrata de valor e vitalidade transcendentes, e que, de outro, há múltiplas experiências que são diretamente ligadas à situação do leitor e ao objeto no qual o texto o texto é lido". (CHARTIER, 1999, p. $70-71)$.

Essa afetividade que Chartier (1999) destaca, deduz o que podemos falar do caráter de humanização do ensino da literatura, à medida que essa leitura considera as palavras e as imagens. Trata do estabelecimento das relações com outras áreas de conhecimento, a arte, a música, o jogo de imagens, até porque o letramento literário à luz dos multiletramentos caminha por esse viés, o de considerar todos os modos de leitura, valorizando os dois aspectos, o estético e a linguagem.

Avaliações do Saeb (Brasil, 2012), acerca da leitura, apontou dados, que se de um lado os alunos são capazes de lidar com informações explicitas em um texto, por outro, muitos jovens são capazes de usar tais competências apenas em textos simples. Há um clamor dos professores de que os jovens não leem, não gostam de ler e cada vez mais se afastam da leitura. A esse despeito concordamos com Chartier se acordamos com o que seja a leitura. Pois os que são considerados não leitores, com certeza leem, porém não leem as leituras que a sociedade quer, que o cânone recomenda como a boa leitura, como uma leitura legítima. Nesse sentido, citamos novamente Chartier (1999) que afirma o seguinte:

O problema não é tanto o de considerar como não-leituras estas leituras selvagens que se ligam a objetos escritos de fraca legitimidade cultural, mas é o de tentar apoiar-se sobre essas práticas incontroladas e disseminadas para conduzir esses leitores, pela escola mas também sem dúvida por múltiplas outras vias, a encontrar outras leituras. É preciso utilizar aquilo que a norma escolar rejeita como um suporte para dar acesso à leitura na sua plenitude, isto é, ao encontro de textos densos e mais capazes de transformar a visão do mundo, as maneiras de sentir e de pensar. (CHARTIER, 1999, p. 104). 
Os resultados da prova Brasil (2012) confirmam a posição de Chartier (1999) quando sinaliza as dificuldades do aluno com o encontro da leitura com os textos mais elaborados e densos, e a necessidade de ações pontuais com vistas nas competências leitoras dos alunos. Hoje já não podemos aceitar que uma "simples atividade de leitura seja considerada atividade escolar de leitura literária” (COSSON, 2014a, p. 26) e nem tão pouco ser empecilho para o processo de letramento literário na escola. O Plano de Desenvolvimento da Educação: Prova Brasil, explica que a "[...] a leitura é fundamental para o desenvolvimento de outras áreas do conhecimento e para o consequente exercício da cidadania" (BRASIL, 2008, p. 21).

Cabe-nos refletir acerca das práticas escolares atuais das aulas de literatura, em que de um lado, há os currículos imensos e impostos como expõem muitos professores, escolas sem estruturas nas salas de aula e bibliotecas e até mesmo sem acervos bibliográficos, cargas horárias reduzidas para a disciplina e referenciais metodológicos pautados num ensino estruturalista, que privilegiam as fichas de leituras, as famosas listagens de obras, escolas literárias, autores e datas, e de outro, alunos que precisam se preparar para as avaliações do Enem e estão chegando no ensino médio com deficiências leitoras.

As experiências diversas de leituras realizadas no ensino fundamental, na maioria das vezes, a leitura mais frequente, não é a do impresso, nem a leitura considerada a legítima pela escola. Encontramos duas realidades que precisam ser resolvidas: a metodológica por parte da escola, e a aprendizagem da literatura via leitura por parte do aluno. Pois, diante dos referenciais teóricos, observa-se que no que tange à questão da leitura e da literatura há dois saberes que caminham lado a lado, porém estes, muitas vezes não se juntam numa única direção, e que inúmeras são as vezes que a escola não considera os conhecimentos e os valores culturais que o aluno traz. Nesse sentido, voltemos a Chartier (1999) que nos aponta o seguinte:

Temos, portanto, os ensinamentos da escola, e de um lado as aprendizagens fora da escola, seja a partir de uma cultura escrita já denominada pelo grupo social, seja por uma conquista individual que é sempre vivida como um distanciamento frente ao meio familiar e social e, ao mesmo tempo, como uma entrada em um mundo diferente. (CHARTIER, 1999, p. 105).

Façamos nossas, as perguntas de Chartier a despeito do livro e da leitura. Um livro existe sem leitores? Ele pode até existir como objeto, mas, sem leitor, o texto do qual ele é portador é apenas virtual. Será que o mundo do texto existe quando não há ninguém para dele se apossar, para dele fazer uso, para inscrevê-lo na memória ou para transformálo em Experiência? E veremos o quão necessário é o desenvolvimento de um trabalho literário voltado para o despertar do gosto da leitura, do desenvolvimento das competências leitoras dos alunos, textos bons que os levem a ter interesse e à discussão, em que a leitura seja vista como uma interação, um diálogo existente entre a obra, o autor e o leitor.

Podemos concordar com Cosson no sentido de que "ler é um diálogo que se mantem com a experiência do outro. Ler é um processo, uma aprendizagem sobre a 
construção do mundo, do outro e de nós mesmos em permanente devenir. Ler é movimento" (COSSON, 2014b, p. 174).

A literatura, como a pensamos, para além da disciplina precisa ser vista, entendida, trabalhada com metodologias capazes de provocar o gosto, o interesse, o sentir, o viver, o despertar de habilidades que proporcionem o encontro do leitor com a obra. Desta forma, com certeza, mesmo tendo poucas aulas semanais, currículos impostos, a escassez de obras literárias nas escolas, ausências de bibliotecas, a presença de textos ditos "impróprios" para as leituras escolares, a tarefa de ler e fazer ler se cumprirá, e nessa esteira podemos afirmar com Cosson que

[...] ler não tem contraindicação, porque é o que nos faz humanos. Todas as formas de ler valem a pena. Todas as formas de ler são diálogos entre o passado e o presente. Todas as formas de ler são modos de compartilhar saberes, experiências e concepções da vida e do mundo. Os círculos de leitura são espaços de compartilhamento organizados para que o diálogo em torno de uma obra seja também um lugar onde leitores se reconheçam como membros de uma comunidade. (COSSON, 2014b, p. 179).

No lócus da escola, para que a literatura cumpra seu papel de desenvolver as competências leitoras, ela precisa ser pensada de maneira adequada, ir além dos resumos, das fichas e entrar no processo da interação, como um conjunto de práticas sociais cujos "leitores envolvidos nessas práticas constroem relações de identidade e poder." (KLEIMAN, 2008 p. 11). Esse conceito de Kleiman assinala o ponto alto do letramento, e a importância do ensino de literatura nas escolas ser no conjunto de práticas sociais, e com a finalidade de inserção na sociedade. Uma boa metodologia deve propiciar ações para que o aluno saiba escrever uma carta, emitir sua opinião, assistir a um filme legendado, apropriar-se da internet para a interação com o outro.

Essa relação da literatura literária com as práticas sociais vem, de certa maneira, fortalecer o aluno do ensino médio a sair da manipulação imposta pela sociedade. Assim, cumpre não esquecer as avaliações realizadas por Chiappini (1983) em seu livro Invasão da catedral: literatura e ensino em debate. A estudiosa, naquela ocasião, já responsabilizava o professor como mediador do conhecimento, com o dever de explanar as potencialidades do texto literário e criar condições para que o aluno absorva plenamente o sentido que o texto literário proporciona para não ser somente mais um na sociedade.

Outro aspecto implicado nessa relação do ensino de literatura e o letramento literário é o de sensibilizar o aluno para as questões estéticas, a criticidade e a consciência ética. Formar cidadão crítico, consciente e ético para a sociedade hoje, movimenta o papel da escola e a metodologia de ensino dos professores, no sentido de relacionar o que se ensina na escola com a realidade desse aluno. Pinheiro (2001, p. 301), ao refletir sobre o letramento literário aponta que a questão maior está na matriz curricular da Educação Básica, pois essa disciplina tem que retratar a "concepção pedagógica da instituição escolar e da prática docente daqueles interessados em assumir a tarefa de formar leitores literários".

Já é possível encontrar em alguns documentos, como os Parâmetros Curriculares Nacionais $(\mathrm{PCN})$ e as Orientações Curriculares Nacionais (OCN), principalmente na 
(OCN) que trata do ensino médio, o predomínio para uma prática de autoridade/valorização do letramento crítico e ético.

Atualmente, em relação ao ingresso do estudante na escola, algumas questões se impõem: que jovens estamos recebendo no ensino médio? Eles realmente não leem, ou estão vivenciando um mundo de multiletramento? O que se considera hoje como leitura propícia? Um torpedo? Um outdoor? Um whatsapp? Uma canção? Um filme legendado? Uma propaganda virtual? Estamos diante de jovens no ensino médio mediados pela leitura e escrita de práticas sociais diversificadas, que denominamos de práticas de letramentos variados e significativos na constituição de sujeitos com diferentes papéis sociais. O que pressupõe é que muitas dessas práticas não estão sendo reconhecidas pela escola, permanecendo uma situação de "invisibilidade".

No tocante ao ensino médio, aponta Souza et al (2012) que o ensino esbarra com questões políticas, aspectos técnicos e humanos que impedem uma ação eficaz, pois as escolas ainda continuam de salas de aulas lotadas, professores se lotam em muitas séries, com ausência de salas de leituras, laboratórios, internet, o que torna difícil a aproximação da realidade vivenciada pelos alunos fora dos espaços da escola, com as que encontram no interior delas.

A leitura, como instrumento primeiro de produção de significados deve ser o elemento central de todas as aulas de literatura para despertar interesse, emoção e desejos nos sujeitos ali envolvidos; professores, alunos, autores e obras, fazendo com que haja interação surgindo, assim, novos e outros significados. Dessa forma, poderemos indagar que tipo de ensino estamos oferecendo aos nossos alunos, e teremos a certeza de termos uma resposta significativa e coerente com os paradigmas de um ensino pautado na diversidade, no significado, na emoção, na multiplicidade de sentidos, modos e culturas, no interesse na literatura que o aluno quer ler e não somente na literatura que nós queremos, que nós entendemos que seja a melhor.

\section{O LETRAMENTO LITERÁRIO E OS MULTILETRAMENTOS}

Buscar compreender o letramento literário à luz dos multilletramentos é pensar em um ensino pautado em alguns benefícios, como por exemplo, o de inserir na prática pedagógica um planejamento que envolva uma multiplicidade de linguagens, gêneros, culturas e instrumentos, de acesso aos bens culturais, à comunicação e à informação. Isso porque o cotidiano das escolas, na contemporaneidade se apresenta muito mais adverso, dinâmico, com uma pluralidade híbrida de gêneros, suportes e culturas, diferentes do século XIX, em que as teorias da aprendizagem eram cerceadas a objetividade.

A literatura encontra nesse espaço de pluralidade de linguagens, um campo fértil para convivência com diversos gêneros, enfatizando essa ideia de hibridização dos gêneros, fundamentada sobre os ensinamentos de Kleiman (2004, p.19), quando explica que letramento trata de "um conjunto de práticas sociais que usam a escrita, enquanto sistema simbólico e enquanto tecnologia, em contextos específicos, para objetivos específicos." Ao entender que o letramento são práticas sociais, em espaços específicos não estamos considerando qualquer campo, mas o campo da literatura, no seu aspecto da 
ficcionalidade e como tal podemos dizer que encontramos multiplicidades de culturas e com isso vários exemplos de letramento literário.

Quando falamos em multiplicidade de culturas, reportamo-nos a Canclini (2008, apud ROJO; Moura, 2012, p.13-14), quando explica que somos rodeados de "produções culturais letradas em efetiva circulação social", caracterizando a ideia de vários textos híbridos, circulando, ou seja, uma harmoniosa aceitação dos diferentes letramentos: o popular, o erudito, o clássico, o moderno, o da periferia, o impresso, o virtual. Veja que a produção cultural permeia um processo em "sociedades de híbridos impuros, fronteiriços", uma hibridação que possibilitada que cada professor possa fazer seu próprio planejamento, "sobretudo a partir das novas tecnologias". (CANCLINI, 2008, apud ROJO; MOURA, 2012, p. 16). Assim, faz-se necessária a adoção de nova postura diante das questões éticas e estéticas, considerando os conceitos de propriedade e direitos autorais, na interpretação e na recepção das produções, bem como a referência ao aceitar as preferências do outro e a apreciação de valor estético das coleções postas.

O que podíamos dizer de uma classificação de gêneros literários programados, com o advento das ferramentas tecnológicas. Essa categorização ultrapassa os muros da escola, uma vez que os usuários ganham acesso às produções culturais de várias naturezas, oportunizando acesso a novos textos que requerem outros letramentos de caráter multi, hiper, como por exemplo: hipertextos, hipermídias, oportunizando novas e múltiplas formas de produção e de leituras literárias, pois esses novos hiper e multi possuem características interativas proporcionando um vínculo: leitor, autor, obra; nesse sentido, Rojo e Moura (2012), explicam:

Uma das principais características dos novos (hiper) textos e (multi) letramentos é que eles são interativos, em vários níveis (na interface, das ferramentas, nos espaços em rede dos hipertextos e das ferramentas, nas redes sociais). Diferentemente das mídias anteriores (impressas e analógicas como a fotografia, o cinema, o rádio e a TV pré-digitais), a mídia digital, por sua própria natureza "tradutora" de outras linguagens para a linguagem dos dígitos binários e por sua concepção fundante em rede (web), permite que o usuário (ou o leitor/produtor de textos humanos) interaja em vários níveis e com vários interlocutores (interface, ferramentas, outros usuários, textos/discursos etc). (ROJO e MOURA, 2012, p. 23).

Essa possibilidade de criação de novos textos, com o impacto de novas mídias e tecnologias é o que possibilita a criação dos termos multiletramento: a multissemiose ou multimodalidade, em outras palavras "textos compostos de muitas linguagens (ou modos, ou semioses) e que exigem capacidades e práticas de compreensão e produção de cada uma delas (multiletramentos) para fazer significar" (ROJO; MOURA, 2012, p. 19).

Nesse contexto da contemporaneidade podemos encontrar a literatura inserida nesse ambiente plural, que vai se apropriar desses novos modos de elaborar textos literários, por meio do uso das imagens, do som ou da simbiose de todas essas modalidades. Isso é o que mostra o poder do multiletramento, subsidiando o fazer pedagógico dos professores como um desafio para o ensino com novas práticas de ensino e aprendizagem. Esse desafio se coloca ao professor, pois trata de conhecer a organização de um trabalho multimidiático, os saberes do professor para poder ensinar essa nova 
prática, ou conforme explica Lemke, (2010 apud ROJO; MOURA, 2012, p. 20): "Vários letramentos e tradições culturais combinam essas modalidades semióticas diferentes para construir significados que são mais do que a soma do que cada parte poderia significar separadamente". No dizer de Lemke (2010) por isso multiplicador combinando multimídia, áudio, vídeo, animações, música, voz, além do que uma editora poderia fazer em um livro.

Quando Canclini (2008, p. 308 apud ROJO; MOURA 2012, p. 16) aponta para a necessidade de "descoleção e de hibridação" está convidando o professor para ser um "agente desmocratizador dos letramentos" (denominação dos autores), pois com essa denominação o professor passa ser o dono das suas escolhas, do conteúdo a ser utilizado com gêneros digitais, que muitas vezes não são contemplados no livro didático, são, na verdade, desvalorizados e em muitos casos, estigmatizados e rejeitados. O que torna viável uma "descoleção", ou seja, sair da coleção pronta, estigmatizada, para outras que promovam as práticas orais e escritas letradas solicitadas socialmente. Assim, dentre os gêneros da literatura digital podemos encontrar "poesia hipertextual, ciberpoesia, hiperconto, minicontos, imagens cotidianas, como expansão do letramento literário". (MARTINS DIAS, apud ROJO e MOURA (orgs), 2012, p.101).

Uma literatura que envolva as modalidades semióticas chama atenção para a necessidade da reestruturação da escola, do professor e da sala de aula. Já não se concebe mais um ensino que não considere as mudanças ontológicas, epistemológicas oriundas das novas tecnologias. Kalantzis e Cope (2006 apud Rojo e Moura (orgs), 2012, p. 100 em seu texto Multiliteracies: Literacy Learning and the Design of Social Futures, defendem a ideia de se trabalhar com projetos de literatura, que considerem as diferenças culturais dos alunos não deixando de considerar as diferentes dimensões: pessoal, cívica e participativa, só assim se justifica um trabalho com a literatura sob viés dos multiletramentos.

Cosson (2014) em seu livro Círculos de leitura e Letramento literário reúne observações e reflexões de leitura coletiva de textos literários, fruto de suas experiências com alunos do ensino médio. Essa expressão Círculo, foi citada por Cosson (2014) para denominar os cursos, oriundos dos Projetos de Extensão realizados entre 1999 a 2001. Assim relata a metodologia de suas ações:

Todas as atividades do curso eram preparadas antecipadamente nas aulas da disciplina Metodologia do Ensino de Literatura. Os alunos desta disciplina formavam uma equipe conforme o número de participantes das turmas divididos em grupos de quatro a cinco pessoas. Para cada grupo, deveria haver um coordenador. Os textos usados, contos e poemas eram selecionados tendo como base a bagagem cultural dos alunos de Letras e, sempre que possível, uma sondagem da formação de leitor dos participantes. As atividades pedagógicas de leitura de cada texto baseavam-se em quatro passos. O primeiro consistia em um aquecimento ou motivação em forma de oficina textual, ou seja, uma atividade prática destinada a produzir um texto oral ou escrito relacionado com o texto literário que seria lido em seguida. No segundo passo, discutia-se o texto, lido previamente em casa, com os grupos. $O$ terceiro era o registro dessa interpretação por escrito. $O$ quarto consistia no compartilhamento das leituras dos grupos em um debate geral de toda a turma, visando à formação de uma comunidade interpretativa. No final do curso, os participantes preenchiam um formulário de avaliação da atividade e vários deles registraram o contentamento em participar das discussões que geravam a interpretação coletiva do texto literário, destacando 
como eram diferentes das aulas de literatura que haviam experienciado na escola. (COSSON, 2014b, p. 7).

Trata de uma experiência que cumpria dois objetivos: proporcionar aos futuros licenciados em Letras uma forma de prática docente supervisionada e oferecer aos alunos do Ensino Médio um encontro e reencontro com o texto literário. Foram encontros sistematizados em espaços diferentes: sala de aula, biblioteca, pequenos aptos, clube do livro, livrarias, praças shopping, restaurantes, supermercados entre outros.

Nesse sentido, Cosson (2014), considera o círculo de leitura, como uma prática pedagógica distinta de reconhecimento de uma leitura coletiva. Nessa perspectiva o multiletramento aparece a partir da leitura dos textos literários que consideram as diferentes multissemiose e/ou multimodalidade presentes na leitura. O pesquisador considera três pontos essenciais como uma maneira de compreender o trabalho com o letramento literário: "[...] c caráter social da interpretação dos textos [...] o estreitamento dos laços sociais, e o reforço das identidades e da solidariedade entre as pessoas [...] pois os círculos de leitura possuem um caráter formativo.” (COSSON, 2014b, p. 139). Na prática de círculos de leitura o encontro do autor, obra e leitor é dinâmico, significativo e contribui para a construção conjunta de conhecimento.

Diante do avanço das comunicações, da tecnologia, das transformações da sociedade, que ensino de literatura a escola está oferecendo? Está olhando o aluno, considerando sua visão de mundo, sua criatividade? Qual o nível de criatividade está despertando em seus alunos, está dando espaço para que o aluno leia, que sinta prazer de ler, e nesse contexto o que está sendo oferecido para que o aluno leia? A literatura que a escola considera boa, a que é considerada cultura?

A literatura precisa ser encarada como fonte de cultura não apenas como espetáculo, mas também, e sobretudo, como propulsora de conhecimentos, entretenimento, reflexão libertação, arte, fonte de desejos, emancipação. Por meio da leitura literária o ser humano pode ousar a sonhar e tem a possibilidade de desvendar mistérios, descobrir que o mundo é muito maior que a imaginação é capaz de chegar e também muito mais plural e emocionante.

Faz-se necessário que toda a riqueza que está embrenhada na literatura seja desnudada para que o aluno, de forma simples, reflexiva, consciente, respeitosa e criativa, num processo de ensino e aprendizagem que considere as diferenças, as igualdades, os vários suportes em que as liberdades são disponibilizadas. Um ensino que valorize a literatura como a palavra que cria, que ensina, que comunica, que vive, a qual está em todo e qualquer lugar e que sendo encarada dessa forma é possível ver os alunos lendo, pois são motivados a ler, entender e ver literatura, assim, podemos ver em Cosson (2014b, p. 15):

[...] se recuperarmos o sentido da literatura como a palavra qua palavra, independentemente de seu registro ou veículo de transmissão, a situação pode ser bem diferente. É essa concepção básica, de quem argumenta que o que está em processo de obsolescência são as formas que a tradição conhece e valoriza como literárias, um fenômeno mais geral, que se relaciona ao declínio ou reposicionamento do livro no universo cultural. Dessa forma, longe de ter diminuído o seu espaço social, a literatura estaria em nossos dias experimentando uma 
nova forma de alargamento ao ser difundida em diferentes formatos e veículos, usualmente em composição com outra manifestação artística.

$\mathrm{Na}$ atualidade em que a sociedade passa por grandes transformações, faz-se necessário que a escola sinta-se incomodada com um ensino que privilegie apenas o texto canônico e impresso - o livro - e se lance às novas práticas valorizando os textos/obras postas fora do modelo tradicional, introduzindo as multissemioses, multimodalidades e multiculturalidades, bem como os vários suportes em que as obras literárias são disponibilizadas. Nessa perspectiva, a obra literária passa a ter um significado diferenciado, trazendo em si uma gama de sentidos possíveis e de significados que transpõem a mera configuração do texto escrito, posto, via de regra, como a única forma possível e correta, considerada, há muito, como a única verdadeira e digna de ser concebida como literária.

Diante dessa nova visão, da possibilidade de desbravar outros suportes e outras obras literárias, faz-se necessário que a escola tenha uma visão do "novo" literário e conscientize-se de que cada obra é única, significativa e boa naquilo que representa e se faz representar, não havendo, portanto, necessidade de comparações, pois de acordo com Chartier (1999, p. 71) "A obra não é jamais a mesma quando inscrita em formas distintas, ela carrega, a cada vez, um outro significado.” Na trajetória do livro e das obras literárias, na era das novas tecnologias o novo suporte do texto permite usos, manuseios, e intervenções do leitor infinitamente mais numerosos e mais livres do que qualquer uma das formas antigas do livro" (CHARTIER, 1999, p. 88). Diante dessas transformações, há mudanças em todos os sentidos, desde o formato das obras, até a relação do autor, leitor e editor com os textos/obras produzidas, alterando também a ideia de autoria, uma vez que na era digital, das linguagens líquidas e multissemióticas, das produções colaborativas e dos espaços virtuais, a concepção de produção, intervenção e interação com o material produzido não é a mesma, desta forma:

O leitor não é mais constrangido a intervir na margem, no sentido literal ou no sentido figurado. Ele pode intervir no coração, no centro. O que resta então da definição do sagrado, que supunha uma autoridade impondo uma atitude feita de reverência, de obediência ou de meditação, quando o suporte material confunde a distinção entre o autor e o leitor, entre a autoridade e a apropriação? (CHARTIER, 1999, p. 91).

Dessa forma, concordamos com Cosson (2014) que é preciso levar para o ensino da literatura as músicas, os filmes, as histórias em quadrinhos, a literatura eletrônica, o livro, o cânone, pois desta forma a escola estará cumprindo seu papel social, humano, estético, crítico, ético e emotivo, pois ao contrário, se deixar a obra/o texto literário fora das salas de aula, haverá um grande apagamento da literatura enquanto locus de conhecimento, como nos aponta Cosson (2014b):

O resultado de tudo isso é o estreitamento do espaço da literatura na escola e, consequentemente, nas práticas leitoras das crianças e dos jovens. No campo do saber literário, o efeito de tal estreitamento pode ser potencialmente ainda mais desastroso porque a escola é a instituição responsável não apenas pela manutenção e disseminação de obras consideradas canônicas, mas também de protocolos de leitura que são próprios da literatura. 
Se a presença da literatura é apagada da escola, se o texto literário não tem mais lugar na sala de aula, desaparecerá também o espaço da literatura como lócus de conhecimento. (COSSON, 2014b, p. 15).

O ensino da literatura considerando as novas obras, os "avatares" de Cosson (2014b), como a canção popular e seus vários ritmos, os filmes, as histórias em quadrinhos, os nano e minicontos, a literatura eletrônica, significa uma oportunidade de proporcionar aos estudantes conhecimentos significativos, voltados ao alargamento da literatura abrangendo os vários campos culturais da sociedade contemporânea, carecendo, para tanto, de novos conceitos estéticos, havendo a necessidade de se pensar em novas metodologias que deem conta de uma literatura que abranja inúmeras linguagens, semioses, culturas, modalidades e suportes presentes na era tecnológica em que vivemos.

$\mathrm{O}$ estabelecimento de metodologias que valorizem conceitos éticos, estéticos e críticos, se fazem necessários para o estabelecimento de um processo de ensino e aprendizagem que contribua para a promoção da literatura, bem como para a formação de leitores literários críticos, conscientes e engajados.

Focar os novos letramentos emergentes na sociedade e associar essas novas formas de produção de sentido às produções literárias canônicas e tradicionais, favorece novas aprendizagens aos estudantes, e aos professores, oportunidades de rever suas ações, lançando mão de novas práticas que envolvem multissemioses, multimodalidades e multiculturalismos. O ensino do literário, nessa perspectiva possibilita aos estudantes se comunicar linguística e literariamente, considerando e promovendo efeitos de sentidos nos mais variados destinatários, bem como possam ser motivados e "afetados" significativamente pelo conhecimento destes, por seus gostos, preferências, e influências culturais, sociais e históricas, fazendo com que a literatura cumpra seu papel de comunicar, encantar, seduzir, emocionar, produzir e vincular conhecimentos.

\section{CONSIDERAÇÕES}

O estudo teórico realizado proporcionou uma reflexão acerca da docência, da prática pedagógica, das práticas sociais da leitura e do papel do professor na escola. Enquanto a sociedade atual aponta para uma literatura do multiletramento, com a presença de materiais de leitura que vai além dos livros, podemos encontrar multiplicidades de leituras na sociedade como: nas placas de trânsito, e-mails, web, propagandas, jornais, desenhos, enfim, os códigos semióticos presentes estão em todos os espaços.

Considerando a leitura de mundo de Paulo Freire (2006) que precede a leitura da palavra, podemos olhar para um outro mundo, um mundo virtual denominado de Letramento Literário, muito bem explicitado por Cosson (2014) em seu livro Letramento literário: teoria e prática, como um artífice de ensinar, considerando o extra escola, as mídias, os códigos semióticos, porque considerar leitor hoje na escola, não basta ler por fruição um livro ou se aprazer das rimas de uma poesia. Mais do que isso, o letramento literário permite identificar-se e questionar-se "protocolos de leitura, afirmando ou retificando valores culturais, elaborando e expandindo sentidos" (COSSON, 2014a, p.120). 
O letramento literário é um termo mais abrangente do que simplesmente literatura e incorpora o plural dos letramentos, porque trata de usos sociais, a disposição do leitor para sua emancipação. A sua diferença de outros letramentos recai em relação à linguagem e na condição de envolvimento em um contex to da sociedade que lhe proporciona direitos até então não alcançados, conforme ensina (COSSON, 2014a, p.17): um "[...] mundo compreensível transformando a sua materialidade em palavras de cores, odores, sabores e formas intensamente humanas". Essa materialidade está chamando a atenção da atualização permanente do aluno leitor e do professor para uma literatura carregada de sentidos.

No bojo das leituras realizadas podemos mencionar a questão dos programas governamentais que solicitam o ensino de leitura com a literatura, mas por outro lado perdem crédito quando assumem uma concepção autônoma de letramento em seus planos de ação, quando a literatura aponta para um modelo ideológico de letramento, por este ter uma prática voltada para uma prática social. Entendemos que o letramento literário deve ser o norte para o trabalho metodológico da ação docente, uma vez que o letramento literário tem o caráter de utilizar práticas multissemióticas. Assim uma gama de textos presentes na sociedade faz parte do material da literatura, fomentando e criando possibilidades de leituras.

No ensino médio, a matriz curricular contempla uma aula de literatura por semana, para dar conta do conteúdo. Segundo Cosson (2014a, p .22) a literatura no ensino médio se resume a "seguir de maneira descuidada o livro didático, seja ele indicado ou não pelo professor ao aluno", longe de ocorrer de fato o letramento literário. A exemplo, o estudioso menciona a leitura de Lucíola, de José de Alencar, como o intuito de realizar estudos sobre a prostituição, semelhante a outras estratégias como material didático alternativos, para estudos da gramática.

Haverá na escola outras estratégias para o ensino do letramento literário no ensino

médio? A literatura que ora nos debruçamos, aponta caminhos que torna viável enaltecer o valor da literatura, a partir de práticas focadas no letramento literário. Endossamos os argumentos dos pesquisadores Paulino e Cosson (2004, p. 68), que atribui ao professor de literatura a responsabilidade da sensibilidade aos eventos da sociedade para que a literatura desperte a atenção do aluno, ela precisa estar vinculada com a vida, pois, literatura é efetivamente vida". São as relações da leitura com a sociedade que chamamos de letramento literário.

\section{REFERÊNCIAS}

BAKHTIN, M. Os gêneros do discurso. In: BAKHTIN, M. Estética da criação verbal. São Paulo: Martins Fontes, 2003.

BRASIL. Ministério da Educação. PDE: Plano de Desenvolvimento da Educação: Prova Brasil: ensino fundamental: matrižes de referência, tópicos e descritores. Brasília: MEC, SEB; Inep, 2008.

BRASIL. Ministério da Educação. Instituto Nacional de Estudos e Pesquisas Educacionais Anísio Teixeira. Diretoria de Avaliação da Educação Básica. SAEB/Prova 
Brasil 2011 - primeiros resultados. 2012. Disponível em: <http://download.inep.gov.br/educacao_basica/prova_brasil_saeb/resultados/2012/S aeb_2011_primeiros_resultados_site_Inep.pdf>. Acesso em: 2016.

CANCLINI, N. G. Culturas Hibridas - estratégias para entrar e sair da modernidade. Tradução de Ana Regina Lessa e Heloísa Pezza Cintrão. São Paulo: EDUSP, 2008. p. 283-350.

CANDIDO, A. Formação da Literatura Brasileira: momentos decisivos. $6^{\mathrm{a}}$ ed. Belo Horizonte: Editora Itatiaia, 2000.

CHARTIER, R. A aventura do livro: do leitor ao navegador. Tradução Reginaldo de Moraes. São Paulo: Unesp, 1999.

CHIAPPINI, L. Invasão da catedral: literatura e ensino em debate. Porto Alegre: Mercado Aberto, 1983.

COSSON, R. Letramento literário: teoria e prática. São Paulo: Contexto, 2014a.

COSSON, R. Círculos de leitura e letramento literário. São Paulo: Contexto, 2014b.

FREIRE, Paulo. A importância do ato de ler: em três artigos que se completam. 48 ed.

São Paulo: Cortez, 2006.

KALANTZIS, M; COPE, B.(orgs). Multiliteracies: Literacy learning and the design of social futures. London: Routldge, 2006[2000], p121-148.

KLEIMAN, A. B. Introdução: O que é letramento? Modelos de letramento e as práticas de alfabetização na escola. In: KLEIMAN, A. B. (org.). Os significados do letramento. São Paulo: Mercado de Letras, 2004

KLEIMAN, A. Texto e leitor: aspectos cognitivos da linguagem. 5. ed. Campinas-SP: Pontes, 2008.

LEMKE, J. L. Letramento metamidiático: transformando significados e mídias. Trabalho de linguística Aplicada. Campinas: 2010, vol 49(2): 455-479, Jul./Dez. pp.455-479. Capturado em:http://www.scielo.br/pdf/tla/v49n2/09.pdf, 11 de setembro de 2016.

MARTINS D, A. V. Hipercontos multissemioticos. In: ROJO, Roxane Helena R; MOURA, Eduardo (Orgs.). Multiletramentos na escola. São Paulo: Parábola Editorial, 2012. p. $95-122$.

PAULINO, G.; COSSON, R (Org.). Leitura literária: a mediação escolar. Belo Horizonte: Faculdade de Letras da UFMG, 2004.

PINHEIRO, A. Letramento literário: da escola para o social e do social para a escola. In: GONÇALVES, A. V.; PINHEIRO, A. S. (orgs.). Nas trilhas do letramento. Campinas: Mercado das Letras, 2001, p. 281-297.

REZENDE, N. L. de. O ensino de literatura e a leitura literária. In: DALVI, Maria Amélia; REZENDE, N. L. de; JOVER-FALEIROS, R. (Orgs.). Leitura de literatura na escola. São Paulo: Parábola, 2013.

ROJO, R. Letramentos múltiplos, escola e inclusão social. São Paulo: Parábola, 2009. 
ROJO, R. H. R; MOURA, E. (Orgs.). Multiletramentos na escola. São Paulo: Parábola Editorial, 2012.

ROUXEL, A. Aspectos metodológicos do ensino da literatura. In: DALVI, Maria Amélia; REZENDE, N. L. de; JOVER-FALEIROS, Rita (Orgs.). Leitura de literatura na escola. São Paulo: Parábola, 2013

SOUZA, A. L. S.; CORTI, A. P.; MENDONÇA, M. Letramentos no ensino médio. São Paulo: Parábola, 2012.

Recebido em: 03/06/2018 Aprovado em: 15/10/2018

Publicado em: 31/12/2018 